Check for updates

Cite this: RSC Adv., 2017, 7, 20824

Received 23rd January 2017

Accepted 27th March 2017

DOI: 10.1039/c7ra01014a

rsc.li/rsc-advances

\section{Preparation of conductive microfiltration membrane and its performance in a coupled configuration of membrane bioreactor with microbial fuel cell $\uparrow$}

\author{
Lihua Huang, (D) abc Xiufen Li, (D)*ac Yueping Ren ${ }^{\text {ac }}$ and Xinhua Wang (D) ac
}

A conductive flat microfiltration membrane (G-FM) was prepared with polyvinylidene fluoride (PVDF), Nmethyl-2-pyrrolidone (NMP), polyvinyl pyrrolidone (PVP) and reduced graphene oxide (RGO) on stainless steel mesh base by the method of immersion-precipitation phase transformation. The pure water flux and mean pore size of the prepared G-FM were $712 \pm 62 \mathrm{~L} \mathrm{~m}^{-2} \mathrm{~h}^{-1}$ bar $^{-1}$ and $0.09 \pm 0.01 \mu \mathrm{m}$, respectively. Equipped with the prepared G-FM, the coupled configurations of membrane bioreactor (MBR) with microbial fuel cell (MFC) removed 96.6\% $\pm 3.9 \% \mathrm{COD}, 95.8 \% \pm 5.7 \% \mathrm{NH}_{3}-\mathrm{N}$ and $94.7 \% \pm$ $5.2 \%$ total nitrogen and generated $349 \pm 19 \mathrm{~mW} \mathrm{~m}^{-2}$ bioelectricity from the synthetic municipal wastewater. Moreover, the membrane fouling was reduced due to enhanced hydrophilicity and electrostatic repulsive forces. The coupled configuration with the G-FM presents a bright future in the field of wastewater treatment and greatly promotes the practical application of MBR and MFC.

\section{Introduction}

Microbial fuel cell (MFC) is a technology that uses exoelectrogens onto the anode to oxidize organic or reduced inorganic matter from waste streams and produces renewable energy in the form of bioelectricity. ${ }^{1-3}$ However, it is not sufficient as a standalone wastewater treatment process to achieve satisfactory effluent quality, and the effluent requires further treatment to meet the relevant requirements for water quality.,5 Compared with the conventional activated sludge process, a membrane bioreactor (MBR) uses a membrane module for separation of solid from liquid, and higher sludge concentration has the capability of initiating a series of biological reactions to simultaneously remove organic carbon and nitrogen. It was of special interest due to excellent quality effluent, a smaller footprint and less waste-activated sludge and is gaining more and more popularity in the context of wastewater reclamation and reuse. However, there are still some issues, such as inevitable membrane fouling, higher energy consumption for aeration and stability for long-term operation, which limit its widespread application. ${ }^{6-8}$

${ }^{a}$ Laboratory of Environmental Biotechnology, School of Environmental and Civil Engineering, Jiangnan University, Wuxi 214122, PR China. E-mail: xfli@jiangnan. edu.cn; Tel: +8651085326516

${ }^{b}$ School of Agriculture and Forestry Science, Linyi University, Linyi 276005, PR China 'Jiangsu Key Laboratory of Anaerobic Biotechnology, Wuxi 214122, PR China

$\dagger$ Electronic supplementary information (ESI) available. See DOI: 10.1039/c7ra01014a
The combined configuration of MFC with MBR proposed recently has potential to simultaneously supply qualified water and bioelectricity from wastewater. For example, the waste stream is first passed through MFC and then through MBR for further treatment to achieve qualified effluent in the two-stage MFC and MBR system., ${ }^{9,10}$ Essentially, MFC and MBR were independent and spatially separated in those systems, leading to a larger footprint. Then, the integral hybrid MFC-MBR reactors appeared, which contained conductive membrane, such as conductive ultrafiltration membrane bio-cathode, ${ }^{5}$ polypyrrole and 9,10-anthraquinone-2-sulfonic acid modified stainless steel mesh cathode membrane, ${ }^{\mathbf{1 1}}$ reduced graphene oxide (RGO)/polypyrrole modified polyester cathode membrane, ${ }^{\mathbf{1 2}}$ an effective cathode membrane with carbon fiber cloth, polyvinylidene fluoride (PVDF) and a catalyst containing $\mathrm{C}, \mathrm{Mn}, \mathrm{Fe}$ and $\mathrm{O}$ elements, ${ }^{13}$ and stainless steel mesh with biofilm. ${ }^{14}$ The conductive membranes played a dual role by serving as the filter membrane in MBR and the cathode in MFC. However, the abovementioned conductive membranes were not traditional filter membranes. The stability and durability of these conductive membranes were of great concern in longterm operation, and nitrogen removal was not mentioned in those investigations.

In this manuscript, we prepared a conductive flat microfiltration membrane using a mixture of PVDF, $\mathrm{N}$-methyl-2pyrrolidone (NMP) and polyvinyl pyrrolidone (PVP) with RGO on a stainless steel mesh base by the method of immersionprecipitation phase transformation, herein, called RGO-flat membrane (G-FM). The fundamental performance parameters 
of G-FM accorded with traditional membranes. Equipped in single-chamber MFC reactors, the prepared G-FM functioned as a microfiltration membrane for MBR and a cathode for MFC, successfully integrating MBR and MFC together for treatment of synthetic municipal wastewater. A higher pollutant removal efficiency was achieved in the coupled configurations, which also synchronously outputted bioelectricity.

\section{Experimental section}

\subsection{Preparation of the G-FM}

First, $84 \mathrm{~mL}$ NMP (Sinopharm Chemical Reagent Co., Ltd, China), $4 \mathrm{~g}$ PVP $\left(M_{\mathrm{w}}=40000 \mathrm{Da}\right.$, Sinopharm Chemical Reagent Co., Ltd, China) and $12 \mathrm{~g}$ PVDF (FR904, $M_{\mathrm{w}}=2.0 \times 10^{6} \mathrm{Da}, M_{\mathrm{n}}=$ $6.0 \times 10^{5} \mathrm{Da}$, Shanghai 3F New Materials Co., Ltd, China) were transferred to a $250 \mathrm{~mL}$ three-neck round flask in turn, and the solution was stirred ( $400 \mathrm{rpm})$ for $24 \mathrm{~h}$ at $60{ }^{\circ} \mathrm{C}$. The addition of RGO to conventional casting membrane solution (CMS) was believed to make microfiltration membrane conductive, whereas overdosing RGO inevitably impacted the CMS viscosity and further the pore size of the prepared membrane. After the dosage of RGO was optimized, $5 \mathrm{~g}$ RGO was dispersed into the above solution, sonicated (KQ500DA, Kunshan, China) for $6 \mathrm{~h}$ at $400 \mathrm{~W}$, and stirred $(400 \mathrm{rpm})$ for $24 \mathrm{~h}$ at $60{ }^{\circ} \mathrm{C}$ to obtain homogeneous CMS. After fully degassing for $48 \mathrm{~h}$, CMS was accurately casted at a thickness of $300 \mu \mathrm{m}$ on a stainless steel mesh (above, 300 mesh, Shanghai Teson Sieving Filtrating Equipment Co., Ltd, China) and polypropylene non-woven base (below, $40 \mu \mathrm{m}$ average pore size, $100 \mathrm{~nm}$ thickness, $60 \mathrm{~g} \mathrm{~m}^{-2}$, Shanghai SINAP Membrane Science and Technology Co., Ltd, China) using a coating machine (FA-102, Shanghai Fuan Enterprise Development Co., Ltd, China), wherein the stainless steel mesh served as current collector and polypropylene nonwoven fabric as the supporting base. Then, the membrane precursor obtained was immediately immersed in a coagulation bath (here distilled water) for $48 \mathrm{~h}$ at $25{ }^{\circ} \mathrm{C}$ to remove all the residual solvent by refreshing distilled water frequently, and the prepared G-FM was finally obtained. The preparation process is demonstrated in Fig. S1.† RGO nanosheets were prepared with natural graphite powder (100 mesh) by a modified Hummers method (Fig. S2†). ${ }^{15}$

\subsection{Reactors and operation}

The plexi-glass reactors had a total effective volume of $28 \mathrm{~mL}$ and were constructed as previously described. ${ }^{16}$ Two types of reactors were equipped with the prepared G-FM cathodes and operated in open (G-FM open $)$ and closed circuit (G-FM closed $_{\text {) }}$ modes, respectively. As controls, another two types of reactors were established with commercial flat membranes (FM, Jiangsu Lantian Peier Membrane Co., Ltd, China) and Pt/C electrodes to replace the G-FM cathodes, and the commercial FM reactors were also in open circuit. Therefore, the commercial FM and G$\mathrm{FM}_{\text {open }}$ served as $\mathrm{MBR}$, the $\mathrm{Pt} / \mathrm{C}$ reactors as $\mathrm{MFC}$, and the prepared G-FM $\mathrm{F}_{\text {closed }}$ reactors were coupled configurations of MBR and MFC. The Pt/C cathode was prepared according to previous literature by applying platinum $\left(0.5 \mathrm{mg} \mathrm{cm} \mathrm{cm}^{-2} \mathrm{Pt}\right.$,
Hispec3000, Shanghai Hesen Electric Co., Ltd, China) and four diffusion layers (polytetrafluoroethylene, PTFE) on a wetproofed carbon cloth (HCP330P, Shanghai Hesen Electric Co., Ltd, China). ${ }^{17}$ The graphite felt anode $(3.0 \mathrm{~cm}$ diameter, $0.5 \mathrm{~cm}$ thickness, Beijing Sanye Carbon Co., Ltd, China) with a projected area of $7 \mathrm{~cm}^{2}$ was positioned in parallel opposite to the cathode across an external resistance of $1000 \Omega$ in Pt/C and G$\mathrm{FM}_{\text {closed }}$ reactors. The commercial FM and G-FM were fixed by the end plates with $0.3 \mathrm{~cm}$ diameter hole and bolted together with "O ring" rubber gasket. The holes served as the air channel for the oxygen reduction reaction (ORR) of the cathode and also enabled removal of the effluent under applied TMPs across FM at the end of each reaction cycle.

The G-FM $M_{\text {closed }}$ and Pt/C reactors were inoculated with $\mathbf{1 4 . 0}$ $\mathrm{mL}$ effluent from the existing well-running MFC (originally seeded with Taihu Lake sediment, China) in our lab., and then $14 \mathrm{~mL}$ synthetic municipal wastewater was added. The synthetic municipal wastewater contained glucose $\left(230 \mathrm{mg} \mathrm{L}^{-1}\right)$, peptone $\left(60 \mathrm{mg} \mathrm{L}^{-1}\right)$, sodium acetate $\left(40 \mathrm{mg} \mathrm{L}^{-1}\right)$, beef extract $(20 \mathrm{mg}$ $\left.\mathrm{L}^{-1}\right), \mathrm{NaHCO}_{3}\left(198 \mathrm{mg} \mathrm{L}{ }^{-1}\right), \mathrm{KH}_{2} \mathrm{PO}_{4}\left(12 \mathrm{mg} \mathrm{L}{ }^{-1}\right), \mathrm{NH}_{4} \mathrm{HCO}_{3}$ (170 mg L $\left.{ }^{-1}\right), \mathrm{MgCl}_{2} \cdot 6 \mathrm{H}_{2} \mathrm{O}\left(2.4 \mathrm{mg} \mathrm{L}^{-1}\right), \mathrm{CaCl}_{2}\left(1.2 \mathrm{mg} \mathrm{L}^{-1}\right)$ and $\mathrm{FeCl}_{3} \cdot 6 \mathrm{H}_{2} \mathrm{O}\left(1 \mathrm{mg} \mathrm{L}{ }^{-1}\right)$, with COD of $377 \pm 8 \mathrm{mg} \mathrm{L}^{-1}$ and electrical conductivity of $893 \pm 24 \mu \mathrm{S} \mathrm{cm}^{-1}$. After the G-FM $\mathrm{F}_{\text {closed }}$ and $\mathrm{Pt} / \mathrm{C}$ reactors outputted stable voltages for three consecutive cycles, the start-up of MFC reactors was successful. Then, all reactors were inoculated by the mixture of equal anaerobic (with moisture content of $78 \%$ ) and aerobic (with moisture content of $83 \%$ ) sludge with synthetic municipal wastewater, and the final suspended solids (SS) was around $4 \mathrm{~g} \mathrm{~L}^{-1}$. When the outputted

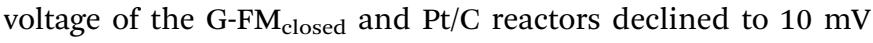
( $\sim 3$ days), the first cycle was over and the effluent was removed for water quality analysis. For the commercial FM, G-FM and $\mathrm{G}-\mathrm{FM}_{\text {closed }}$ reactors, the effluent was filtered through membrane module using peristaltic pumps (YZ1515X-A, Baoding Longer Precision Pump Co., Ltd, China), and the TMP values were measured using a U-shaped mercury manometer. Before filtration, $2.8 \mathrm{~mL}$ of mixture for sludge viability was obtained by a syringe from a sample port at the end of each reaction cycle, and hence the sludge retention time (SRT) was

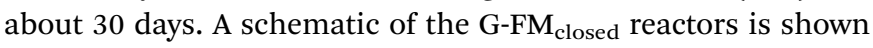
in Fig. 1. For the Pt/C reactors, the effluent was directly poured out of the sample port. All reactors mentioned above were operated in fed-batch mode at $25 \pm 1{ }^{\circ} \mathrm{C}$ under stirring conditions $(100 \mathrm{rpm})$ and each type of reactor was duplicated.

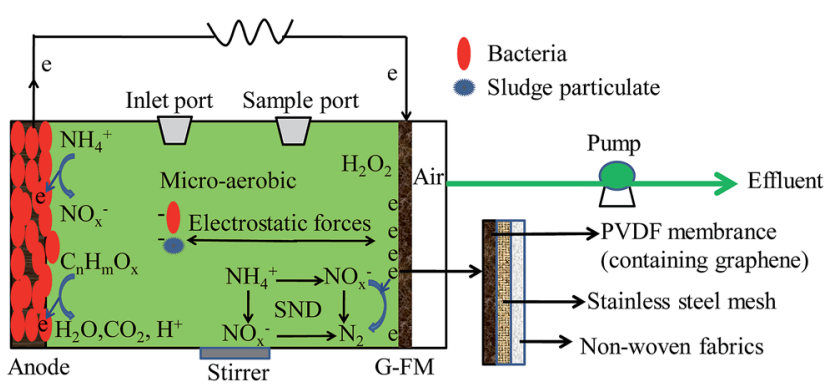

Fig. 1 Schematic of the G-FMclosed reactors. 


\subsection{Analyses}

The electrochemical analyses were performed using an electrochemical workstation (CHI660D, Shanghai Chenhua Instruments Co., Ltd, China) with a three-electrode model, wherein Pt wire was the counter electrode, and a saturated calomel electrode (SCE, type of 232, $0.2244 \mathrm{~V} v$ s. SHE, Shanghai Leici) was the reference electrode. The conductivity of bare cathodes was examined by cyclic voltammetry $(\mathrm{CV})$ in $1 \mathrm{~mol} \mathrm{~L}^{-1} \mathrm{KCl}$ solution (containing $0.05 \mathrm{~mol} \mathrm{~L}^{-1}$ potassium ferricyanide, $\mathrm{pH}=7.0$ ) from -0.2 to $0.8 \mathrm{~V}\left(v s\right.$. SCE) at a scan rate of $5 \mathrm{mV} \mathrm{s}^{-1}$. Linear sweep voltammetry (LSV) was applied to investigate the catalytic activity of cathode for ORR based on onset potential and current density in synthetic municipal wastewater from 0.4 to $-0.5 \mathrm{~V}$ (vs. SCE) at a scan rate of $1 \mathrm{mV} \mathrm{s}^{-1}$. Tafel plots were conducted in synthetic municipal wastewater at a scan rate of $1 \mathrm{mV} \mathrm{s}^{-1}$, with the calculation of exchange current density $\left(j_{0}\right)$ and electron transfer number $(n)$ during ORR according to the method previously described. ${ }^{\mathbf{1 8}, 19}$ Before electrochemical testing, the bare cathode, equipped as working electrode, was immersed in the relevant solution for $24 \mathrm{~h}$. Cell voltage was automatically recorded using a data acquisition unit (34972A, Agilent Technologies Inc, USA) at a pre-determined sampling frequency across an external resistance of $1000 \Omega$. Polarization and power density curves were measured using the LSV method, scanning from open circuit voltage to zero at a scanning rate of $1 \mathrm{mV}$ $\mathrm{s}^{-1},{ }^{20}$ and the individual electrode potential was recorded by another electrochemical workstation synchronously, wherein the maximum power density $\left(P_{\max }\right)$ and current density were normalized by the cathode projected area $\left(7 \mathrm{~cm}^{2}\right)$. Electrochemical impedance spectroscopy (EIS) was conducted over a frequency range of $1 \times 10^{5}$ to $0.005 \mathrm{~Hz}$ under open-circuit voltage, with a sinusoidal perturbation amplitude of $10 \mathrm{mV} .^{21}$ The activity variation of cultured $\mathrm{Pt} / \mathrm{C}$ and G-FM cathodes through the scanning range for ORR was examined by $\mathrm{CV}$ from 0.4 to $-0.8 \mathrm{~V}$ (vs. SCE) at a scanning rate of $1 \mathrm{mV} \mathrm{s}^{-1}$. Using oxygen as electron acceptor, coulombic efficiency (CE) was calculated based on COD removal by a method described by Kim et al. ${ }^{22}$ All of the electrochemical tests in MFC reactors were performed in situ for the purpose of obtaining the testing results closer to those of the actual system. Before electrochemical

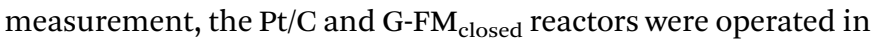
open-circuit mode for over $1 \mathrm{~h}$.

The virgin commercial FM was immersed in deionized water for $48 \mathrm{~h}$ to remove glycerin covered on the surface. Then, the cleaned commercial FM together with the bare G-FM was vacuum freeze-dried for $24 \mathrm{~h}$ (Freezone 1L, Labconco), plunged into liquid nitrogen for $5 \mathrm{~min}$, and then cut into small strips with scissors in liquid nitrogen for morphology observation using a scanning electron microscope (SEM, S-3400N, Hitachi) and element identification using energy dispersive X-ray spectroscopy (EDX). The biofouling layer attached on the membrane or cathode surface was observed using confocal laser scanning microscopy (CLSM, LSM 710, ZEISS) according to a previous study. ${ }^{23}$ Concanavalin A (ConA), calcofluor white (CW), fluorescein isothiocyanate (FITC) and SYTO 63 were used to label $\alpha$ and $\beta$-D-glucopyranose polysaccharides, proteins and total cells, respectively. The hydrophilicity of the commercial FM and GFM was evaluated by measuring the contact angle using the drop shape analysis system (OCA40, Dataphysics Company). A water droplet was deposited on the membrane surface and the instantaneous contact angle obtained within $0.2 \mathrm{~s}$ was recorded to ensure that observable vibration of the liquid drop had already ceased. The contact angle data were the average of measurements at five locations for each sample. ${ }^{24}$ Pure water flux was calculated by $J=Q /(A \times t),{ }^{24}$ where $Q$ is the volume of permeate within time $t(\mathrm{~L}), A$ is the effective area of membrane $\left(\mathrm{m}^{2}\right)$, and $t$ is the time $(\mathrm{h})$. The mean pore size was measured by the filtration velocity method based on the Guerout-ElfordFerry equation, ${ }^{25}$ and the maximum pore size was determined by the bubble point method. ${ }^{26}$ Membrane porosity was measured using a gravimetric method and details of the procedure are available elsewhere. $^{27}$

$\mathrm{COD}, \mathrm{NH}_{3}-\mathrm{N}$ and $\mathrm{TN}$ were analyzed using a spectrophotometer (UV-1800, Shimadzu). ${ }^{28}$ The biomass density was determined by lipid-phosphorus method. ${ }^{29}$ The dissolved oxygen (DO) concentration in reactors was determined by portable detector (Multi 3430, WTW).

\section{Results and discussions}

\subsection{Characterization of the prepared G-FM}

As shown in Fig. S3, $\uparrow$ a clear peak current of the redox reaction for $\mathrm{Fe}^{3+} / \mathrm{Fe}^{2+}$ was observed during $\mathrm{CV}$ scanning of the $\mathrm{Pt} / \mathrm{C}$ and G-FM, indicating that the prepared G-FM was conductive. The conductive path was possibly bridged across the membrane matrix by RGO and a stainless steel mesh, which kept the prepared G-FM conductive. However, the conductivity of the prepared G-FM was slightly inferior to that of the $\mathrm{Pt} / \mathrm{C}$, based on the peak current density and difference of peak potentials. As seen from LSV curves of the bare Pt/C and G-FM cathodes (Fig. 2a), the onset potential was $0.175 \pm 0.032 \mathrm{~V}$ (vs. SCE) for the $\mathrm{Pt} / \mathrm{C}$ and $-0.015 \pm 0.002 \mathrm{~V}$ ( $v s$. SCE) for the prepared G-FM, and the current density of the $\mathrm{Pt} / \mathrm{C}$ cathode was significantly larger than that of the prepared G-FM one. It illustrated that the prepared G-FM had catalytic activity for the ORR, which was inferior to that of the Pt/C. Approximate $j_{0}$ values calculated by Tafel curves (Fig. 2b) were $0.25 \pm 0.03 \mathrm{~mA} \mathrm{~cm}^{-2}$ for the $\mathrm{Pt} / \mathrm{C}$ and $0.14 \pm 0.02 \mathrm{~mA} \mathrm{~cm}^{-2}$ for the prepared G-FM, also showing that the catalytic activity of the prepared G-FM was less effective than that of the Pt/C cathode. The calculated $n$ values were $2.7 \pm 0.4$
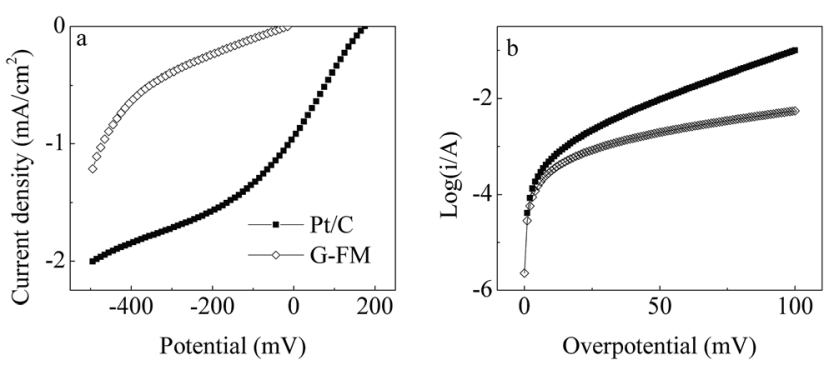

Fig. 2 (a) LSV and (b) Tafel curves of the bare Pt/C and prepared G-FM in synthetic municipal wastewater at a scanning rate of $1 \mathrm{mV} \mathrm{s}^{-1}$. 
for Pt/C and $2.2 \pm 0.3$ for the prepared G-FM cathode. The $n$ value of the $\mathrm{Pt} / \mathrm{C}$ for ORR was nearly 4 in previous literature, wherein the catalyst was uniformly coated on a glassy carbon disk electrode with a diameter of $4 \mathrm{~mm}$ assembled on rotating disk electrode in an $\mathrm{O}_{2}$-saturated environment. ${ }^{19}$ The smaller $n$ value for the $\mathrm{Pt} / \mathrm{C}$ cathode in this study might be associated with non-aerated electrolyte, larger projected area $\left(7 \mathrm{~cm}^{2}\right)$ and lower ionic strength $\left(893 \pm 24 \mu \mathrm{S} \mathrm{cm}^{-1}\right)$. Under the examined conditions, the process for ORR with the Pt/C and G-FM cathodes was mainly dominated by 2 electronic processes, and doping was carried out by more or less 4 electronic processes.

The cross-section structure of the bare commercial FM and prepared G-FM was revealed by SEM observation (Fig. 3). The commercial FM displayed a typical asymmetric morphology, containing a dense skin layer and a porous sub-layer with a finger-like structure (Fig. 3a). ${ }^{30,31}$ The prepared G-FM also displayed an asymmetric morphology. However, with the addition of RGO into CMS and the introduction of stainless steel mesh, the membrane structure was significantly transformed; the section of the prepared G-FM seemed irregular, and the finger-like macropore became much smaller (Fig. 3b).

The contact angles of the commercial FM and G-FM were $74.5^{\circ} \pm 3.7^{\circ}$ and $61.2^{\circ} \pm 2.9^{\circ}$, respectively (Fig. S4 $\dagger$ ), indicating that the prepared G-FM was more hydrophilic. As identified by EDX analysis (Fig. S5 $\dagger$ ), the oxygen content of the prepared GFM reached $4.08 \%$ and was higher than that of the commercial FM (not detected). Due to incomplete oxidation or reduction during the process of preparation, the RGO, prepared by redox method, usually contained a certain number of hydrophilic oxygen-containing groups, such as hydroxyl, carboxyl and carbon-oxygen bonds, ${ }^{32}$ that caused the addition of RGO into CMS to increase the hydrophilicity of the prepared G-FM. The mean and maximum pore sizes diminished to $0.09 \pm 0.01 \mu \mathrm{m}$ and $0.65 \pm 0.06 \mu \mathrm{m}$ for the prepared G-FM and from $0.11 \pm 0.01$ $\mu \mathrm{m}$ and $0.89 \pm 0.08 \mu \mathrm{m}$ for the commercial FM, respectively, with the result that the void ratio and pure water flux declined to $63.9 \% \pm 4.2 \%$ and $712 \pm 62 \mathrm{~L} \mathrm{~m}^{-2} \mathrm{~h}^{-1} \mathrm{bar}^{-1}$ for the prepared G$\mathrm{FM}$ and to $72.3 \% \pm 8.7 \%$ and $1634 \pm 124 \mathrm{~L} \mathrm{~m}^{-2} \mathrm{~h}^{-1} \mathrm{bar}^{-1}$ for the commercial FM, respectively (Table 1).

\subsection{Power generation}

Over about 2 weeks, both Pt/C and G-FM closed $_{\text {reactors started }}$ up successfully with 315 and $221 \mathrm{mV}$ of cell voltages output,
Table 1 Parameters of the commercial FM and prepared G-FM ${ }^{a}$

\begin{tabular}{lcl}
\hline Parameter & Commercial FM & Prepared G-FM \\
\hline Mean pore size $(\mu \mathrm{m})$ & $0.11 \pm 0.01$ & $0.09 \pm 0.01$ \\
Maximum pore size $(\mu \mathrm{m})$ & $0.89 \pm 0.08$ & $0.65 \pm 0.06$ \\
Void ratio (\%) & $72.3 \pm 8.7$ & $63.9 \pm 4.2$ \\
Pure water flux [ $\left.\mathrm{L} \mathrm{m}^{-2} \mathrm{~h}^{-1} \mathrm{bar}^{-1}\right]$ & $1634 \pm 124$ & $712 \pm 62$
\end{tabular}

${ }^{a}$ Values were averages \pm standard errors based on the three pieces of each membrane.

respectively (Fig. 4a). Although the stable outputted voltage of the $\mathrm{Pt} / \mathrm{C}$ reactors was higher than that of the G-FM $\mathrm{F}_{\text {closed }}$ reactors, the discharging time within one reaction cycle for stable outputted voltage in the G-FM closed $_{\text {reactors }(~}$ 58 h) was longer than that in the $\mathrm{Pt} / \mathrm{C}$ ones $(\sim 39 \mathrm{~h})$ at $\geq 100 \mathrm{mV}$, suggesting that the substrate in the $\mathrm{Pt} / \mathrm{C}$ reactors was metabolized more quickly compared with the substrate in G-FM ${ }_{\text {closed }}$ reactors. For the $\mathrm{Pt} / \mathrm{C}$ cathode, oxygen was permitted free access into the reactors via the air diffusion layer, leading to a micro-aerobic environment. ${ }^{17}$ However, the prepared G-FM cathode was infiltrated with water, indicating that there existed a larger resistance for oxygen to diffuse into the G-FM $\mathbf{M}_{\text {closed }}$ reactors across the infiltrated layer. As the results show, the DO concentration in the G$\mathrm{FM}_{\text {closed }}$ reactors at $0.45 \pm 0.08 \mathrm{mg} \mathrm{L}^{-1}$ was lower than that in the $\mathrm{Pt} / \mathrm{C}$ reactors $\left(0.92 \pm 0.13 \mathrm{mg} \mathrm{L}^{-1}\right)$. In the $\mathrm{Pt} / \mathrm{C}$ reactors, the exoelectrogens had to end the stable outputted voltage earlier due to lack of substrate, compared with the case of G-FM closed $_{\text {in }}$ reactors. It suggested that the difference between DO concentration in the $\mathrm{Pt} / \mathrm{C}$ and $\mathrm{G}-\mathrm{FM}_{\text {closed }}$ reactors led to the difference of discharging time for stable outputted voltage. The higher DO concentration may accelerate the substrate degradation rate by non-exoelectrogens. Although the stable outputted voltage in

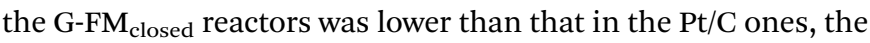

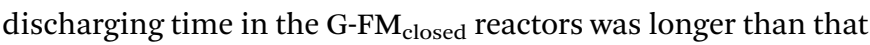
in the $\mathrm{Pt} / \mathrm{C}$ ones. As a result, there was little difference in $\mathrm{CE}$ values with $26.4 \% \pm 3.5 \%$ for the $\mathrm{Pt} / \mathrm{C}$ reactors and $25.6 \pm 3.2 \%$

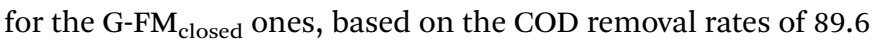
$\pm 7.6 \%$ in the $\mathrm{Pt} / \mathrm{C}$ reactors and $93.7 \pm 6.3 \%$ in the $\mathrm{G}-\mathrm{FM}_{\text {closed }}$ ones.

In the first reaction cycle, the $P_{\max }$ values were $471 \pm 24 \mathrm{~mW}$ $\mathrm{m}^{-2}$ for the $\mathrm{Pt} / \mathrm{C}$ reactors and $349 \pm 19 \mathrm{~mW} \mathrm{~m}^{-2}$ for the G$\mathrm{FM}_{\text {closed }}$ ones (Fig. 5a). At the $23^{\text {rd }}$ reaction cycle (two months later), these declined to $354 \pm 16 \mathrm{~mW} \mathrm{~m}^{-2}$ for the $\mathrm{Pt} / \mathrm{C}$ reactors
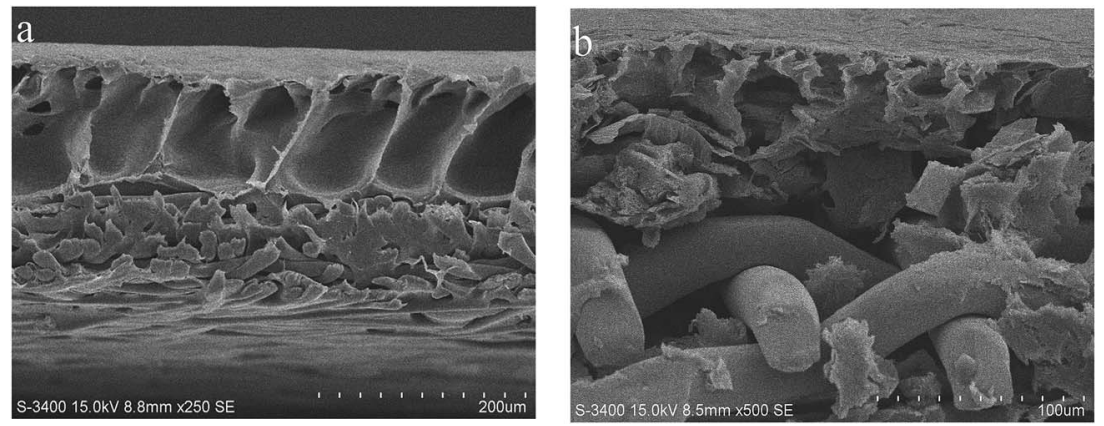

Fig. 3 SEM images of (a) the bare commercial FM and (b) the prepared G-FM. 

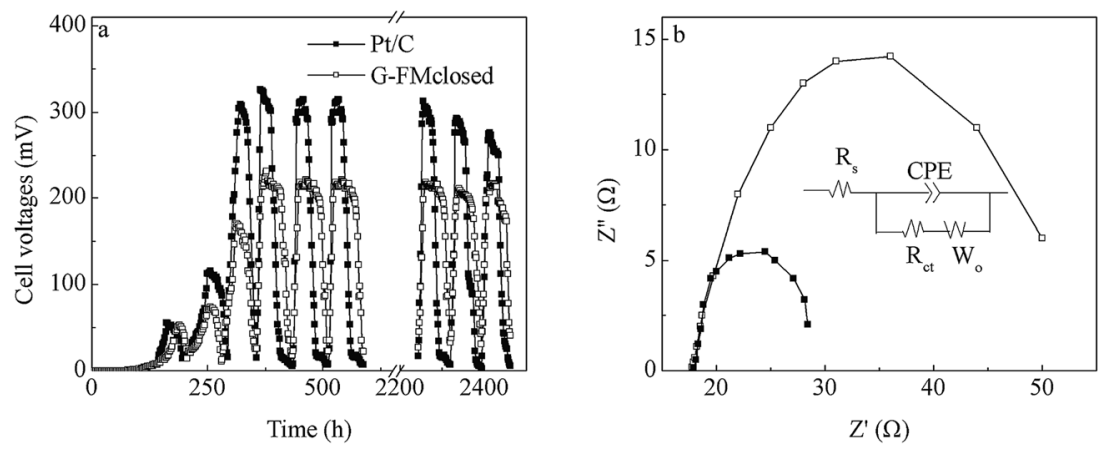

Fig. 4 (a) Profiles of the cell voltage output in the Pt/C and G-FMclosed reactors over time across $1000 \Omega$ external resistor. (b) Nyquist plots of the $\mathrm{Pt} / \mathrm{C}$ and $\mathrm{G}-\mathrm{FM}_{\text {closed }}$ reactors, the inset in (b) is the equivalent circuit.

and $306 \pm 12 \mathrm{~mW} \mathrm{~m}^{-2}$ for the G-FM ${ }_{\text {closed }}$ ones by $24.8 \%$ and $12.3 \%$, respectively (Fig. $5 \mathrm{c}$ ). The $P_{\max }$ value of the $\mathrm{Pt} / \mathrm{C}$ reactors was $33.1 \%$ higher than that of the G-FM $\mathrm{M}_{\text {closed }}$ ones at the first cycle, and it was only $14.0 \%$ after operation for two months. The anode potential of the two types of reactors changed negligibly and the cathode potential presented was quite different (Fig. 5b and d), indicating that the cathode performance was responsible for the variation in power generation. This suggested that the $\mathrm{Pt} / \mathrm{C}$ cathode was more prone to being fouled than the prepared G-FM one, and the previous study had also showed that the catalyst activity of the $\mathrm{Pt} / \mathrm{C}$ cathode decreased in longterm operation due to electrode pollution. ${ }^{33}$ The biomass density on the $\mathrm{Pt} / \mathrm{C}$ cathodes was $6.47 \pm 0.45 \mu \mathrm{g} \mathrm{P}$ per $\mathrm{cm}^{2}$, which was 3.6 times of that on the prepared G-FM, confirming that biofouling of the prepared G-FM cathodes was alleviated compared with that of the $\mathrm{Pt} / \mathrm{C}$ ones. The difference in biomass density was assumed to be associated with the air diffusion efficiency across the cathodes as well as the DO concentration in the two types of reactors.

EIS was applied to analyze the resistance distribution, and it assumed that the cathode reaction was affected by both reaction kinetics and diffusion. A Randle equivalent circuit was usually chosen to model the complex impedance, in which the charge transfer resistance $\left(R_{\mathrm{ct}}\right)$ at the electrode/electrolyte interface was equal to the diameter of the semicircle. ${ }^{34}$ Fig. $4 \mathrm{~b}$ presents the Nyquist plot for the Pt/C and G-FM closed $_{\text {reactors, each of which }}$ showed a semicircle without a straight line following it, demonstrating that the electrode reaction was controlled by the charge transfer step. ${ }^{21}$ The smaller $R_{\mathrm{ct}}$ indicated a faster electron transfer rate between electrode and electrolyte. ${ }^{35}$ By fitting the data of the Nyquist plot using the Zview program, the solution resistance $\left(R_{\mathrm{S}}\right)$ was found to be little different between the Pt/C and G-FM $M_{\text {closed }}$ reactors. The $R_{\text {ct }}$ was $9.6 \pm 0.8 \Omega$ in the 3D-G
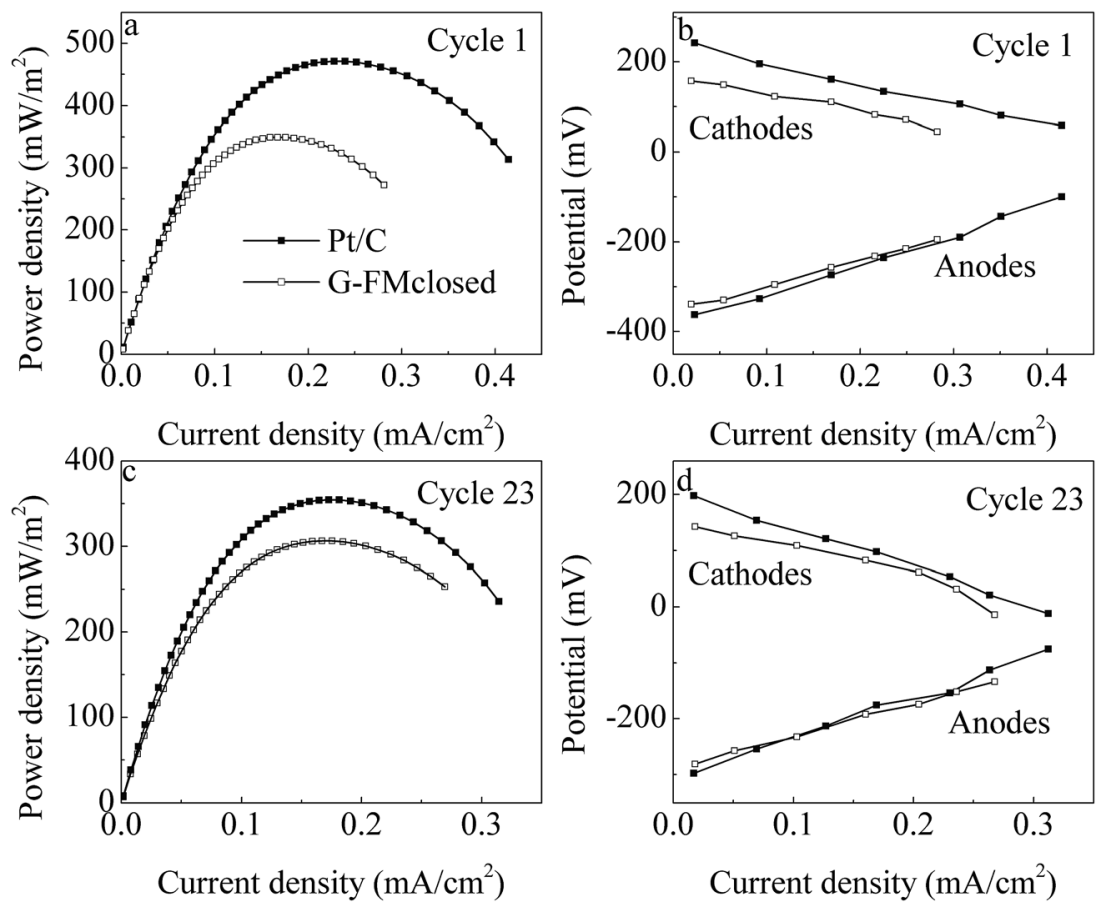

Fig. 5 ( $a$ and $c)$ Power density and ( $b$ and $d$ ) individual potential profiles in the Pt/C and G-FMclosed reactors. 
reactors and $31 \pm 4.5 \Omega$ in the G-FM $_{\text {closed }}$ reactors, which showed that the Pt/C cathode excelled the G-FM $\mathrm{Flosed}_{\text {one. }}$

$\mathrm{CV}$ examination at the second and $20^{\text {th }}$ reaction cycles was conducted to further compare the variation in catalytic activity of the cathode along with operation time (Fig. 6). The variation in the scan current density for the prepared G-FM cathodes was significantly less than that of the $\mathrm{Pt} / \mathrm{C}$ ones, also showing that the catalytic activity of the prepared G-FM for ORR declined less than that of the $\mathrm{Pt} / \mathrm{C}$ over long-term operation. In long-term operation, the prepared G-FM cathodes performed better than $\mathrm{Pt} / \mathrm{C}$ ones and were favorable for sustainable generation of bioenergy.

\subsection{Effluent quality}

After 9 cycles of operation, all reactors were in steady state and the effluent quality was analyzed by concentrations of COD, $\mathrm{NH}_{3}-\mathrm{N}$ and TN (Fig. 7). Due to no filtration, the Pt/C reactors removed the least pollutants with $87.2 \% \pm 4.2 \%$ for COD, $51.3 \%$ $\pm 4.6 \%$ for $\mathrm{NH}_{3}-\mathrm{N}$ and $39.2 \% \pm 3.9 \%$ for TN. The effluent
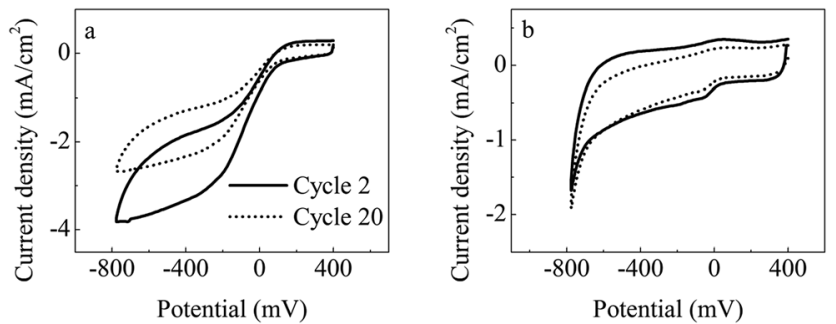

Fig. 6 In situ CV (1 mV s${ }^{-1}$ ) analysis of the cultured Pt/C (a) and G-FM (b) cathodes during operation. quality in the $\mathrm{FM}, \mathrm{G}-\mathrm{FM}_{\mathrm{open}}$ and $\mathrm{G}-\mathrm{FM}_{\text {closed }}$ reactors was significantly superior to that in the $\mathrm{Pt} / \mathrm{C}$ ones. The effluent concentrations of COD, $\mathrm{NH}_{3}-\mathrm{N}$ and $\mathrm{TN}$ were $29.8 \pm 2.4,5.5 \pm$ 0.6 and $21.4 \pm 1.2 \mathrm{mg} \mathrm{L}^{-1}$ in the FM reactors, $23.1 \pm 2.3,4.7 \pm$ 0.5 and $16 \pm 0.8 \mathrm{mg} \mathrm{L}^{-1}$ in the G-FM ${ }_{\text {open }}$ reactors, and $13.6 \pm$ $0.2,1.9 \pm 0.1$ and $3.5 \pm 0.2 \mathrm{mg} \mathrm{L}^{-1}$ in the G-FM closed $_{\text {reactors. }}$ Compared with the $\mathrm{FM}$ and $\mathrm{G}-\mathrm{FM}_{\text {open }}$ reactors, there was

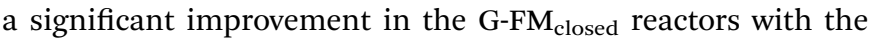
removal efficiency of $96.6 \% \pm 3.9 \%$ for COD, $95.8 \% \pm 5.7 \%$ for $\mathrm{NH}_{3}-\mathrm{N}$ and $94.7 \% \pm 5.2 \%$ for $\mathrm{TN}$, suggesting that the current generation in the G-FM closed $_{\text {reactors enhanced the pollutant }}$ removal efficiency. In the coupled configuration of MBR with MFC established here, the substrate metabolism of both bioanode colonized by exoelectrogens/non-exoelectrogens and suspended sludge in the G-FM $\mathbf{M}_{\text {closed }}$ reactor overlapped the pollutant removal efficiency.

Compared with the previous literature, ${ }^{5,9,14,36,37}$ the excellent nitrogen removal was mainly associated with DO concentration. It demonstrated that the micro-aerobic environment played an important role in nitrogen removal and a DO concentration of around $0.5 \mathrm{mg} \mathrm{L}{ }^{-1}$ was conducive to complete simultaneous nitrification-denitrification (SND), ${ }^{37}$ during which $\mathrm{NH}_{3}-\mathrm{N}$ in synthetic wastewater was oxidized into $\mathrm{NO}_{x}{ }^{-}$and then further into $\mathrm{N}_{2} \cdot{ }^{38,39}$ Air diffused passively into these reactors across the commercial FM and prepared G-FM, resulting in a microaerobic environment. The DO concentrations were $0.53 \pm$ $0.06 \mathrm{mg} \mathrm{L}^{-1}$ for the FM reactors, $0.47 \pm 0.05 \mathrm{mg} \mathrm{L}^{-1}$ for the $\mathrm{G}^{-}$ $\mathrm{FM}_{\text {open }}$ reactors and $0.45 \pm 0.08 \mathrm{mg} \mathrm{L}^{-1}$ for the $\mathrm{G}-\mathrm{FM}_{\text {closed }}$ reactors. The higher DO concentration $\left(0.92 \pm 0.13 \mathrm{mg} \mathrm{L}^{-1}\right)$ in the $\mathrm{Pt} / \mathrm{C}$ reactors had harmed the nitrogen removal. In addition, the anaerobic ammonium oxidation near the bio-anode possibly contributed to TN removal, wherein $\mathrm{NH}_{3}$ could serve
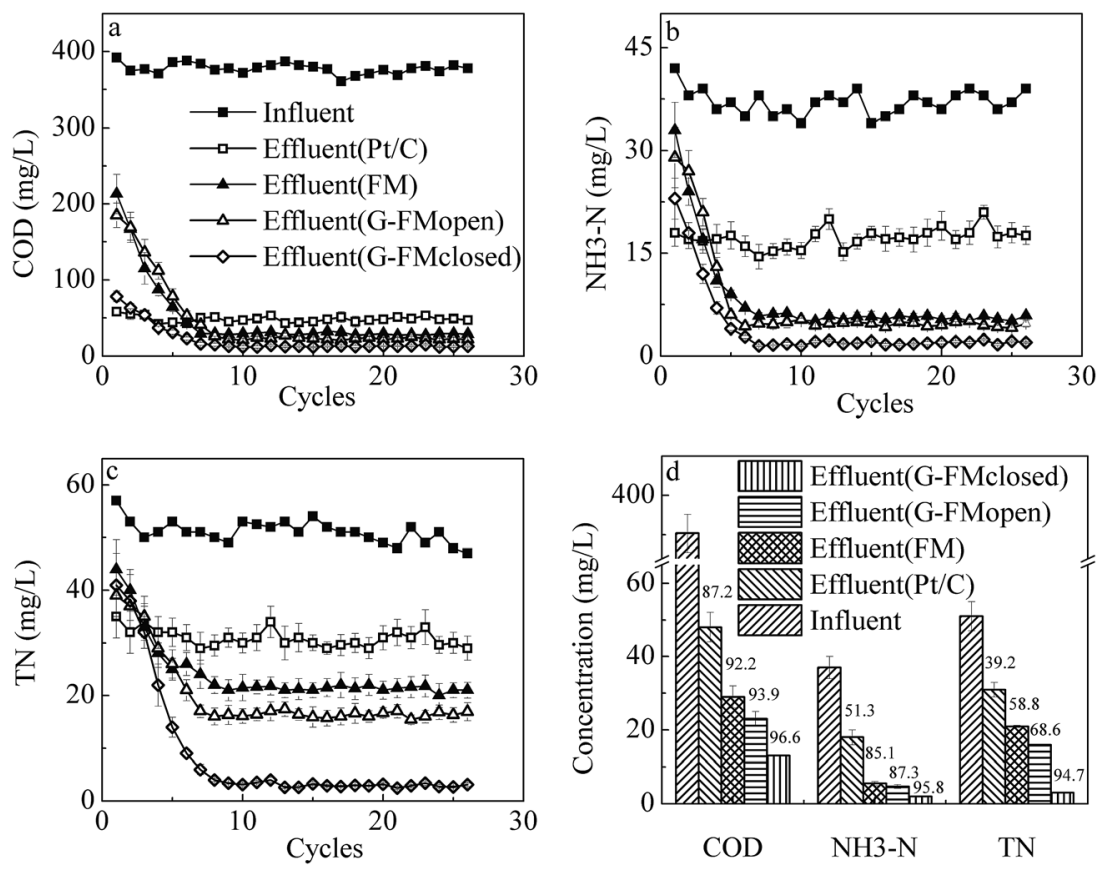

Fig. 7 Removal rate of $\mathrm{COD}(\mathrm{a}), \mathrm{NH}_{3}-\mathrm{N}$ (b) and $\mathrm{TN}$ (c) during operation as well as effluent concentrations of $\mathrm{COD}, \mathrm{NH}{ }_{3}-\mathrm{N}$ and $\mathrm{TN}$ (d). 


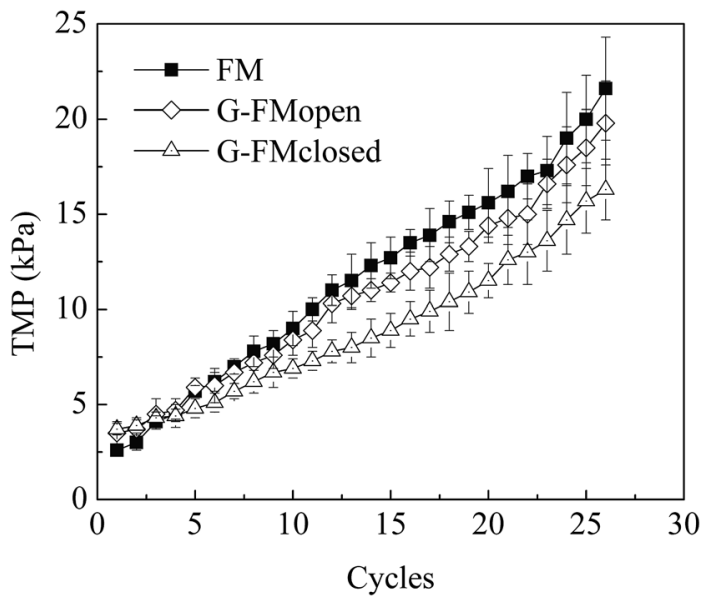

Fig. 8 Profiles of TMP in the FM, G-FMopen and G-FM closed reactors during operation.

as an electron donor and be directly oxidized into $\mathrm{N}_{2}{ }^{40}$ The reduction of $\mathrm{NO}_{x}{ }^{-}$to $\mathrm{N}_{2}$ by denitrification using the cathode as the electron donor also took place..$^{38,39,41}$

\subsection{Membrane fouling}

Over 26 reaction cycles ( $\sim 74$ days) without membrane cleaning, the TMP values measured under constant flux condition increased to $16.3 \pm 1.6 \mathrm{kPa}$ from $3.7 \pm 0.3 \mathrm{kPa}$ in the G-FM $\mathrm{Flosed}$ reactors, to $21.6 \pm 2.7 \mathrm{kPa}$ from $2.6 \pm 0.3 \mathrm{kPa}$ in the $\mathrm{FM}$ reactors, and to $19.8 \pm 2.2 \mathrm{kPa}$ from $3.5 \pm 0.6 \mathrm{kPa}$ in the G-FM reactors (Fig. 8). It indicated that the membrane fouling in the

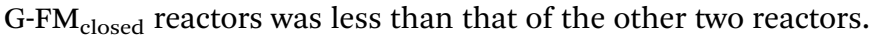
The membrane fouling layer in MBR generally contained an outer bio-cake layer (derived from suspended solid) on the membrane surface and an inner gel layer (derived from soluble microbial polymer or extracellular polymeric substance) within the membrane pores. The former contributed to reversible fouling and the latter to the irreversible fouling (blocking and clogging pores). ${ }^{\mathbf{4 2 , 4 3}}$ The improvement in hydrophilicity of microfiltration membrane was able to weaken the interaction between foulants (colloids or extracellular polymeric substances) and membrane, which further alleviated irreversible fouling. ${ }^{24}$ In this study, it demonstrated that the introduction of RGO into CMS improved hydrophilicity of the prepared G-FM. In addition, there existed electrostatic repulsive forces between the negatively charged bacteria (or sludge) and the electron-loading cathode in the G-FM closed $_{\text {reactors, which was }}$ also conducive to less biofouling. ${ }^{36,44}$ The foulants on the surface of the membrane were possibly oxidized by $\mathrm{H}_{2} \mathrm{O}_{2}$ produced by the cathode reduction, which contributed to alleviating the biofouling. ${ }^{36,44}$ The reconstructed images of the $3 \mathrm{D}$ CLSM in Fig. 9 demonstrated that there was a big difference between the thickness of bio-cake layer on various membranes (or cathodes), with $36 \pm 4 \mu \mathrm{m}$ for the Pt/C, $27 \pm 4 \mu \mathrm{m}$ for the commercial FM, $18 \pm 3 \mu \mathrm{m}$ for the G-FM ${ }_{\text {open }}$ and $16 \pm 2 \mu \mathrm{m}$ for

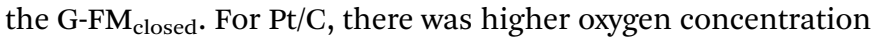
as discussed above, which was beneficial to microorganism proliferation, and the thickness of bio-cake layer was the

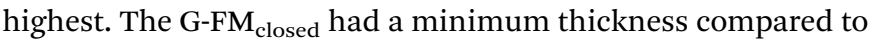
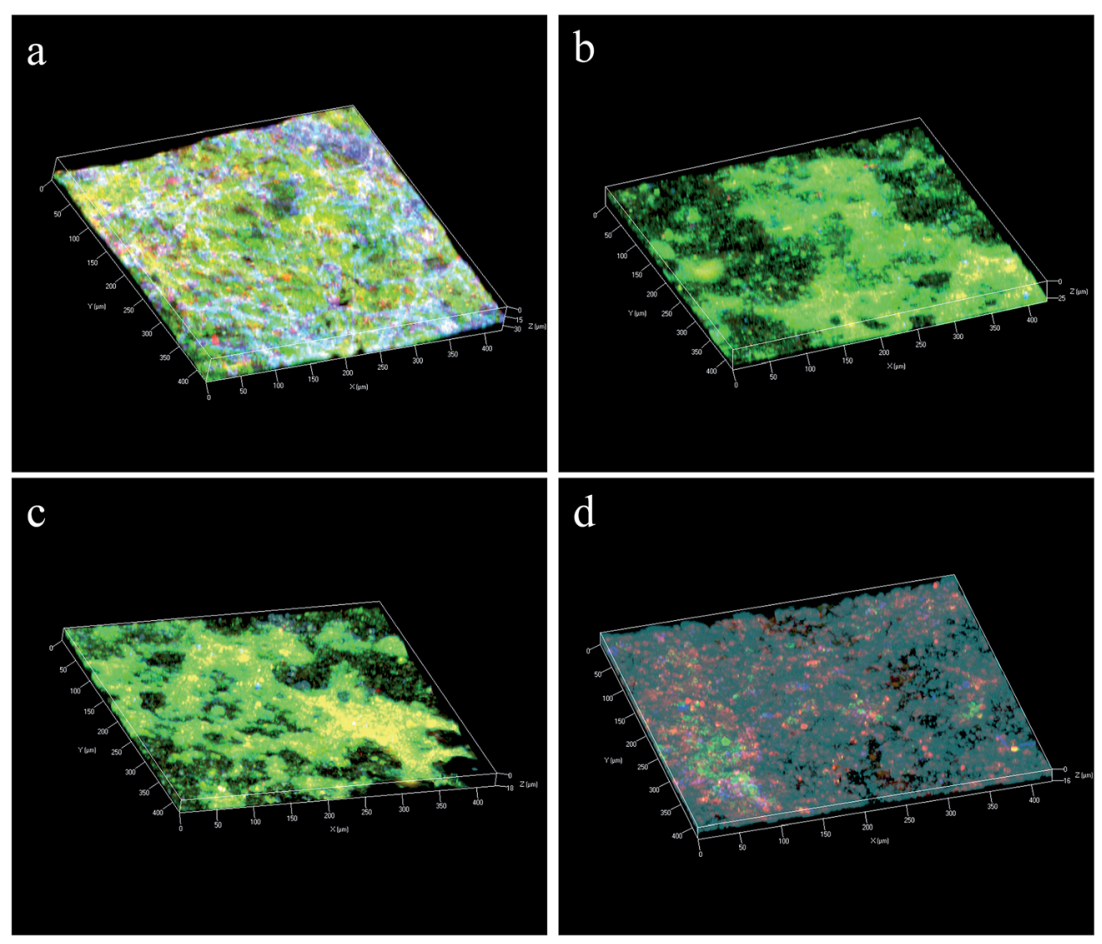

Fig. 9 Integrated CLSM images of polysaccharides, proteins and total cells in the biofouling layer of the Pt/C (a), the commercial FM (b), the G$F M_{\text {open }}$ (c) and G-FM closed (d). Light-blue, blue, green and red colors represent $\alpha$ - and $\beta$-D-glucopyranose polysaccharides, proteins and total cells, respectively. 
the G-FM $\mathrm{open}_{\text {and }}$ ane $\mathrm{FM}$, which was attributed to improved hydrophilicity and electrostatic repulsive forces.

\section{Conclusions}

A conductive flat microfiltration membrane modified with RGO was prepared by the method of immersion-precipitation phase transformation. Equipped with a coupled configuration, the prepared G-FM functioned as a microfiltration membrane for MBR and a cathode for MFC, gaining the removal efficiency of $96.6 \% \pm 3.9 \%$ for COD, $95.8 \% \pm 5.7 \%$ for $\mathrm{NH}_{3}-\mathrm{N}$ and $94.7 \% \pm$ $5.2 \%$ for $\mathrm{TN}$ and synchronously generating $\sim 221 \mathrm{mV}$ cell voltage in the processing of synthetic municipal wastewater. Moreover, the membrane fouling was reduced due to enhanced hydrophilicity and electrostatic repulsive forces between the negatively charged bacteria (or sludge) and the electron-loading cathode.

\section{Acknowledgements}

This study was supported by a grant from the National Key Research and Development Program (2016YFC0400707), the Major Science and Technology Program for Water Pollution Control and Treatment of China (No. 2015ZX07306001-5), the Jiangsu Science \& Technology Pillar Program-Social Development (No. BE2014606), the "Six Major Talent Peaks" of Jiangsu Province (No. 2011-JNHB-004) and the Fundamental Research Funds for the Central Universities (JUSRP51512).

\section{References}

1 A. E. Franks and K. P. Nevin, Energies, 2010, 3, 899-919.

2 M. Zhou, T. Jin, Z. Wu, M. Chi and T. Gu, in Sustainable Bioenergy and Bioproducts, Springer, 2012, pp. 131-171.

3 E. T. Sayed, N. A. M. Barakat, M. A. Abdelkareem, H. Fouad and N. Nakagawa, Ind. Eng. Chem. Res., 2015, 54, 3116-3122.

4 K. P. Katuri, C. M. Werner, R. J. Jimenez-Sandoval, W. Chen, S. Jeon, B. E. Logan, Z. Lai, G. L. Amy and P. E. Saikaly, Environ. Sci. Technol., 2014, 48, 12833-12841.

5 L. Malaeb, K. P. Katuri, B. E. Logan, H. Maab, S. P. Nunes and P. E. Saikaly, Environ. Sci. Technol., 2013, 47, 11821-11828.

6 S. Judd, Trends Biotechnol., 2008, 26, 109-116.

7 Z. Wang, Z. Wu and S. Tang, Water Res., 2009, 43, 2504-2512. 8 S. J. Kim, S. Yang, G. K. Reddy, P. Smirniotis and J. Dong, Energy Fuels, 2013, 27, 4471-4480.

9 L. Ren, Y. Ahn and B. E. Logan, Environ. Sci. Technol., 2014, 48, 4199-4206.

10 Y. Tian, C. Ji, K. Wang and P. Le-Clech, J. Membr. Sci., 2014, 450, 242-248.

11 Y. Li, L. Liu, J. Liu, F. Yang and N. Ren, Desalination, 2014, 349, 94-101.

12 L. Liu, Z. Feng, J. Liu and F. Yang, J. Membr. Sci., 2013, 437, 99-107.

13 Y. Li, L. Liu, F. Yang and N. Ren, J. Membr. Sci., 2015, 484, 2734.
14 Y. K. Wang, G. P. Sheng, W. W. Li, Y. X. Huang, Y. Y. Yu, R. J. Zeng and H. Q. Yu, Environ. Sci. Technol., 2011, 45, 9256-9261.

15 D. C. Marcano, D. V. Kosynkin, J. M. Berlin, A. Sinitskii, Z. Sun, A. Slesarev, L. B. Alemany, W. Lu and J. M. Tour, ACS Nano, 2010, 4, 4806-4814.

16 H. Liu and B. E. Logan, Environ. Sci. Technol., 2004, 38, 40404046.

17 S. Cheng, H. Liu and B. E. Logan, Electrochem. Commun., 2006, 8, 489-494.

18 H. Dong, H. Yu, X. Wang, Q. Zhou and J. Sun, J. Chem. Technol. Biotechnol., 2013, 88, 774-778.

19 H. Dong, H. Yu and X. Wang, Environ. Sci. Technol., 2012, 46, 13009-13015.

20 Y. Wang, B. Li, L. Zeng, D. Cui, X. Xiang and W. Li, Biosens. Bioelectron., 2013, 41, 582-588.

21 Z. He and F. Mansfeld, Energy Environ. Sci., 2008, 22, 175456921.

22 J. R. Kim, B. Min and B. E. Logan, Appl. Microbiol. Biotechnol., 2005, 68, 23-30.

23 B. Yuan, X. Wang, C. Tang, X. Li and G. Yu, Water Res., 2015, $75,188-200$.

24 C. Zhao, X. Xu, J. Chen, G. Wang and F. Yang, Desalination, 2014, 340, 59-66.

25 J. Huang, K. Zhang, K. Wang, Z. Xie, B. Ladewig and H. Wang, J. Membr. Sci., 2012, 423, 362-370.

26 S. Darvishmanesh, F. Tasselli, J. C. Jansen, E. Tocci, F. Bazzarelli, P. Bernardo, P. Luis, J. Degrève, E. Drioli and B. Van der Bruggen, J. Membr. Sci., 2011, 384, 89-96.

27 J. A. Kharraz, M. Bilad and H. A. Arafat, J. Membr. Sci., 2015, 475, 91-100.

28 A. P. H. Association, A. W. W. Association, W. P. C. Federation and W. E. Federation, Standard methods for the examination of water and wastewater, American Public Health Association, 1915.

29 P. Aelterman, S. Freguia, J. Keller, W. Verstraete and K. Rabaey, Appl. Microbiol. Biotechnol., 2008, 78, 409-418.

30 D. J. Lin, C. L. Chang, F. M. Huang and L. P. Cheng, Polymer, 2003, 44, 413-422.

31 V. Vatanpour, S. S. Madaeni, L. Rajabi, S. Zinadini and A. A. Derakhshan, J. Membr. Sci., 2012, 401, 132-143.

32 J.-F. Dai, G.-J. Wang and C.-K. Wu, Chromatographia, 2014, 77, 299-307.

33 K. Fricke, F. Harnisch and U. Schroeder, Energy Environ. Sci., 2008, 1, 144-147.

34 T. Springer and I. Raistrick, J. Electrochem. Soc., 1989, 136, 1594-1603.

35 Z. He and F. Mansfeld, Energy Environ. Sci., 2009, 2, 215-219. 36 Y. K. Wang, W. W. Li, G. P. Sheng, B. J. Shi and H. Q. Yu, Water Res., 2013, 47, 5794-5800.

37 E. V. Münch, P. Lant and J. Keller, Water Res., 1996, 30, 277284.

38 B. Virdis, K. Rabaey, R. A. Rozendal, Z. Yuan and J. Keller, Water Res., 2010, 44, 2970-2980.

39 H. Yan, T. Saito and J. M. Regan, Water Res., 2012, 46, 22152224. 
40 Z. He, J. Kan, Y. Wang, Y. Huang, F. Mansfeld and K. H. Nealson, Environ. Sci. Technol., 2009, 43, 3391-3397.

41 R. R. Sayess, P. E. Saikaly, M. El-Fadel, D. Li and L. Semerjian, Water Res., 2013, 47, 881-894.

42 L. Chu and S. Li, Sep. Purif. Technol., 2006, 51, 173-179.
43 H. Choi, K. Zhang, D. D. Dionysiou, D. B. Oerther and G. A. Sorial, Sep. Purif. Technol., 2005, 45, 68-78.

44 J. Huang, Z. Wang, J. Zhang, X. Zhang, J. Ma and Z. Wu, Sci. Rep., 2015, 5, 9268. 